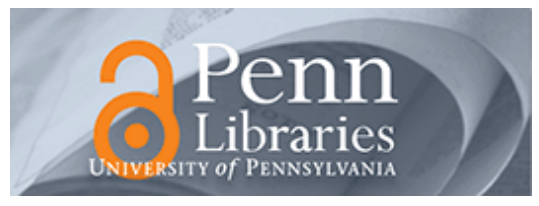

University of Pennsylvania

ScholarlyCommons

Marketing Papers

Wharton Faculty Research

$5-1992$

\title{
Utility Measurement: Configural-Weight Theory and the Judge's Point of View
}

\author{
Michael H. Birnbaum \\ Gregory Coffey \\ Barbara A. Mellers \\ University of Pennsylvania \\ Robin Weiss
}

Follow this and additional works at: https://repository.upenn.edu/marketing_papers

Part of the Behavioral Economics Commons, Cognition and Perception Commons, Cognitive Psychology Commons, Experimental Analysis of Behavior Commons, and the Marketing Commons

\section{Recommended Citation}

Birnbaum, M. H., Coffey, G., Mellers, B. A., \& Weiss, R. (1992). Utility Measurement: Configural-Weight Theory and the Judge's Point of View. Journal of Experimental Psychology: Human Perception and Performance, 18 (2), 331-346. http://dx.doi.org/10.1037/0096-1523.18.2.331

This paper is posted at ScholarlyCommons. https://repository.upenn.edu/marketing_papers/243

For more information, please contact repository@pobox.upenn.edu. 


\title{
Utility Measurement: Configural-Weight Theory and the Judge's Point of View
}

\author{
Abstract \\ Subjects judged the values of lotteries from 3 points of view: the highest price that a buyer should pay, the \\ lowest price that a seller should accept, and the "fair" price. The rank order of judgments changed as a \\ function of point of view. Data also showed violations of branch independence and monotonicity \\ (dominance). These findings pose difficulties for nonconfigural theories of decision making, such as \\ subjective expected utility theory, but can be described by configural-weight theory. Configural weighting \\ is similar to rank-dependent utility theory, except that the weight of the lowest outcome in a gamble \\ depends on the viewpoint, and 0-valued outcomes receive differential weighting. Configural-weight theory \\ predicted the effect of viewpoint, the violations of branch independence, and the violations of \\ monotonicity, using a single scale of utility that is independent of the lottery and the point of view.

\section{Disciplines} \\ Behavioral Economics | Business | Cognition and Perception | Cognitive Psychology | Experimental \\ Analysis of Behavior | Marketing
}




\title{
Utility Measurement: Configural-Weight Theory and the Judge's Point of View
}

\author{
Michael H. Birnbaum \\ Irvine Research Unit in Mathematical Behavioral Sciences and \\ California State University, Fullerton \\ Gregory Coffey \\ California State University, Fullerton \\ Barbara A. Mellers and Robin Weiss \\ University of California, Berkeley
}

File: pov-42

Date: June 20, 1991

Mailing Address:

\author{
Prof. Michael H. Birnbaum \\ Department of Psychology \\ C. S. U.F. \\ Fullerton, CA 92634
}

Phones: $\quad$ 714-773-2102

714-773-3514 (messages)

Bitnet:_ LBIRNBA@CALSTATE 


\begin{abstract}
Subjects judged the values of lotteries from three points of view: the highest price a buyer should pay, the lowest price a seller should accept, and the "fair" price. The rank order of judgments changed as a function of point of view. Data also showed violations of branch independence and monotonicity (dominance). These findings pose difficulties for nonconfigural theories of decision making, such as subjective expected utility theory, but can be described by configural-weight theory. Configural weighting has similarities to rankdependent utility theory, except that the weight of the lowest outcome in a gamble depends on the viewpoint, and zero-valued outcomes receive differential weighting. Configuralweight theory predicted the effect of viewpoint, the violations of branch independence, and the violations of monotonicity, using a single scale of utility that is independent of the lottery and the point of view.
\end{abstract}


In order to study how people evaluate and choose among alternatives, experimental psychologists have investigated judgments of lotteries. With lotteries, one can manipulate what appear to be crucial ingredients in judgment and decision making: the alternatives, the outcomes, and probabilities of the outcomes. Gambles therefore seem to provide a fruitful paradigm for the investigation of decisions (Savage, 1954; Stigler, 1950a, 1950b; von Neumann \& Morgenstern, 1947; Edwards, 1954; Fishburn, 1970, 1983; Kahneman \& Tversky, 1979; Keeney \& Raiffa, 1976; Slovic, Lichtenstein, \& Fischhoff, 1988; von Winterfeldt \& Edwards, 1986).

For example, suppose that a fair coin will be tossed and if the outcome is Heads, then \$96 will be won; otherwise, no money is won. How much should a buyer be willing to pay for this lottery, which offers a .5 chance to win $\$ 96$ ? Although the expected value is $\$ 48$, few people say they would pay more than $\$ 35$ to buy this gamble. One of the enduring problems in the psychology of decision making is to understand the difference between the expected values of lotteries and the values that people place on them. The major explanation of such "risk aversion,” a preference for a sure gain over a gamble with the same expected value, has been the theory that the utility of money is nonlinear (e.g., Becker \& Sarin, 1987; Keeney \& Raiffa, 1976).

Although utility theories have proved helpful to those who advise decision makers what they should do, utility theories have run into difficulty explaining how people actually do make judgments and decisions (Allais, 1979; Birnbaum \& Sutton, in press; Edwards, 1954; Ellsberg, 1961; Kahneman \& Tversky, 1979; Karmarkar, 1978; Luce, in press-a; Machina, 1982; Miyamoto, 1989; Payne, 1973; Schoemaker, 1982; Shanteau, 1974; 1975; Slovic, Lichtenstein, \& Fischhoff, 1988; Tversky \& Kahneman, 1986; von Winterfeldt \& Edwards, 1986). The present experiment will explore configural-weight theory, which may be able to explain certain results that have posed difficulty for expected utility theories. Subjective Expected Utility Theory 
Subjective expected utility (SEU) theory attempts to explain empirical phenomena in the evaluation and choice among gambles by postulating psychophysical transformations of both probability and monetary amounts. Subjective expected utility (SEU) can be written:

$$
\mathrm{SEU}=\Sigma \mathrm{s}\left(\mathrm{p}_{\mathrm{i}}\right) \mathrm{u}\left(\mathrm{x}_{\mathrm{i}}\right)
$$

where SEU is the subjective expected utility of the gamble; $\mathrm{s}\left(\mathrm{p}_{\mathrm{i}}\right)$ and $\mathrm{u}\left(\mathrm{x}_{\mathrm{i}}\right)$ are the subjective probability of outcome $\mathrm{x}_{\mathrm{i}}$ with numerical probability $\mathrm{p}_{\mathrm{i}}$; and $\mathrm{u}\left(\mathrm{x}_{\mathrm{i}}\right)$ is the utility of receiving an outcome with objective value $\mathrm{x}_{\mathrm{i}}$.

Subjective expected utility theory, as written in Equation 1, provides a very flexible, general formulation that includes many interesting special cases and variations. Subjective expected utility theory usually assumes that $\Sigma \mathrm{s}\left(\mathrm{p}_{\mathrm{i}}\right)=1$, although this assumption is not always imposed. The objective values are usually defined as changes from a current value in psychological applications, although they are sometimes defined as final states of wealth in certain applications (Edwards, 1954). If $\mathrm{s}\left(\mathrm{p}_{\mathrm{i}}\right)=\mathrm{p}_{\mathrm{i}}$, then Equation 1 reduces to expected utility (EU) theory; if $\mathrm{u}\left(\mathrm{x}_{\mathrm{i}}\right)=\mathrm{x}_{\mathrm{i}}$, then SEU reduces to subjective expected value (SEV); and if both of these assumptions are made, SEU reduces to expected value (EV) theory.

Figure 1 illustrates the concept of "risk aversion” in Expected Utility theory. Suppose the judge decides that a 50-50 chance to receive \$96 or \$0 is worth \$24. In EU theory, this indifference would be interpreted as follows:

$$
\mathrm{u}(\$ 24)=.5 \mathrm{u}(\$ 0)+.5 \mathrm{u}(\$ 96) .
$$

In EU theory, the judge would be said to be “risk averse” because the expected value (\$48) would be preferred to the gamble. In EU theory, risk aversion is explained by a negatively accelerated utility function, as illustrated in Figure 1. We can calibrate the scale so that $\mathrm{u}(\$ 0)=0$ and $\mathrm{u}(\$ 96)=1$; hence, $\mathrm{u}(\$ 24)=.5$. Therefore, we can construct the $\mathrm{u}(\mathrm{x})$ function through the point $(\$ 24, .5)$, as shown by the leftmost curve in Figure 1 . With more gambles, $\mathrm{u}(\mathrm{x})$ could be determined with greater precision, and the rank order of gambles would satisfy a measurement structure that would define $\mathrm{u}(\mathrm{x})$ to an interval scale (Krantz, Luce, Suppes, \& Tversky, 1971). 
Insert Figure 1 about here

In the framework of utility theory, if another person equated the same gamble to $\$ 72$, that case would be called “risk seeking.” Such behavior would be explained by a positively accelerated utility function, as illustrated by the rightmost curve in Figure 1. A person who equates gambles to their expected values is said to be "risk neutral", and would be represented by a linear utility function, shown in the center of Figure 1.

To construct these utility functions, the utility of the gamble was assumed to be .5, based on the assumption in Equation 1 that $\mathrm{s}(.5)=.5$, and the conclusion followed that the utility function was concave or convex, depending on the judge’s behavior. However, results that imply nonlinear utility functions under EU theory do not necessarily require nonlinear utility functions in configural-weight theory.

\section{Configural-Weight Theory}

Configural-weight theory is a rival theory to parallel-averaging models (Birnbaum \& Stegner, 1979; 1981), such as SEU and its variants. In configural theories, the weight of a stimulus component depends on the relationship between that component and the pattern of other stimulus components presented (Birnbaum, 1972; 1973; 1974; 1982; Birnbaum, Parducci, \& Gifford, 1971; Birnbaum \& Veit, 1974). Configural weighting can account for results that are incompatible with additive models; it does not equate attitudes toward risk with the utility function; and it can yield different measurement scales of utility. Configuralweight theory is closely related to dual bilinear utility theory and rank-dependent utility theory (Chew, Karni \& Safra, 1987; Lopes, 1990; Luce \& Narens, 1985; Luce \& Fishburn, in press; Quiggin, 1982; Karni \& Safra, 1987; Wakker 1989; Yaari, 1987), which were developed independently.

Luce and Narens (1985) derived dual bilinear utility theory as the most general representation of its class that is compatible with interval scales of utility. They showed that 
dual-bilinear utility theory accommodates many findings that have been taken as evidence against expected utility theory. Luce (in press, b) presented a rank- and sign-dependent theory that generalizes prospect theory (Kahneman \& Tversky, 1979). See also Luce and Fishburn (in press).

To illustrate configural weighting, it is instructive to consider gambles of the form: win $\mathrm{x}$ if event A occurs; otherwise, receive $\mathrm{y}$. These gambles will be denoted, (xAy); when the objective probability of event $A$ is specified, the gambles will be written, (xpy), where $\mathrm{p}$ is the probability of receiving x. Gambles that hinge on two equally likely events (“50-50”) gambles will be denoted (x, .5, y). According to a simple configural-weight theory, called the range model (Birnbaum, et al., 1971), the utility of such lotteries can be written as follows:

$$
\mathrm{U}(\mathrm{x}, .5, \mathrm{y})=.5 \mathrm{u}(\mathrm{x})+.5 \mathrm{u}(\mathrm{y})+\mathrm{w}|\mathrm{u}(\mathrm{x})-\mathrm{u}(\mathrm{y})|,
$$

where $w$ is the weight of the range term. As noted by Birnbaum (1974, p. 559), the range model can be interpreted as rank- dependent configural weighting. When $u(x)>u(y)$, Equation 2

can be written as follows:

$$
\mathrm{U}(\mathrm{x}, .5, \mathrm{y})=(.5+\mathrm{w}) \mathrm{u}(\mathrm{x})+(.5-\mathrm{w}) \mathrm{u}(\mathrm{y}) ;
$$

when $\mathrm{u}(\mathrm{x})=\mathrm{u}(\mathrm{y})$, Equation 2 reduces to:

$$
\mathrm{U}(\mathrm{x}, .5, \mathrm{y})=\mathrm{u}(\mathrm{x})
$$

and when $\mathrm{u}(\mathrm{x})<\mathrm{u}(\mathrm{y})$, it becomes:

$$
\mathrm{U}(\mathrm{x}, .5, \mathrm{y})=(.5-\mathrm{w}) \mathrm{u}(\mathrm{x})+(.5+\mathrm{w}) \mathrm{u}(\mathrm{y}) .
$$

Note that if w is zero, then Equation 2 reduces to EU theory. Expressions 2a, 2b, and 2c are equivalent to dual bilinear utility theory for this case (Luce \& Narens, 1985).

Figure 2 illustrates the effects of w. The upper row of Figure 2 shows U(xAy) as a function of $\mathrm{u}(\mathrm{x})$ with a separate curve for each level of $\mathrm{u}(\mathrm{y})$. The values were calculated from Equation 2, using successive integers from 1 to 9 as the values of $u(x)$ and $u(y)$. In the left-hand panel, $\mathrm{w}=-.5$; in the center panel $\mathrm{w}=0$; in the right-hand panel, $\mathrm{w}=+.5$. Note 
that the change in vertical spread between the curves in the top panels depends on the value of $\mathrm{w}$ : When $\mathrm{w}<0$, the curves diverge to the right; when $\mathrm{w}>0$, they converge to the right. In the extreme cases, the gamble is either as bad as its worst outcome (when $\mathrm{w}=-.5$ ) or as good as its best outcome (when $w=+.5$ ). As the value of $w$ varies from -.5 to 0 , to .5 , the model changes from a minimum model, to an additive model, to a maximum model.

\section{Insert Figure 2 about here}

The center row of panels in Figure 2 illustrates the form of the corresponding indifference curves for each value of w. In each panel, each curve represents the locus of points of $u(x)$ and $u(y)$ that produce a constant value of $U(x A y)$. The indifference curves are piecewise linear functions, with slopes that differ for $\mathrm{x}>\mathrm{y}$ or $\mathrm{x}<\mathrm{y}$, where the changes in slope depend on w.

Birnbaum (1974; 1982) noted it may be possible to fit data from a single finite experiment with the incorrect assumption that $\mathrm{w}=0$, but that this solution would lead to inappropriate estimates of subjective value. If subjective values are known or if they can be assumed to be the same as those that operate in another empirical situation involving the same stimuli, it becomes possible to impose greater constraints to test the model and to estimate $\mathrm{w}$.

To illustrate how assumptions about configural weighting can affect the estimation of utility functions, we applied MONANOVA, a computer program for ordinal analysis of additive models (Kruskal \& Carmone, 1969), to the hypothetical data shown in the top row of Figure 2. The program attempts to find $U^{*}(x)$ and $U^{*}(y)$ such that $U^{*}(x)+U^{*}(y)$ will reproduce the rank order of $\mathrm{U}(\mathrm{xAy})$; in other words, it finds the estimated utility functions according to subjective expected utility theory.

The bottom row of Figure 2 shows the relationship between the estimated $\mathrm{U}^{*}(\mathrm{x})$ function and the "true" $\mathrm{u}(\mathrm{x})$ function, with a separate panel for each value of w. These 
graphs show that the estimated utility function depends strongly on the assumed and actual values of $\mathrm{w}$. When $\mathrm{w}<0, \mathrm{U}^{*}(\mathrm{x})$ is a negatively accelerated function of $\mathrm{u}(\mathrm{x})$; when $\mathrm{w}>0$, $\mathrm{U}^{*}(\mathrm{X})$ is a positively accelerated function of $\mathrm{u}(\mathrm{x})$. This apparent change in $\mathrm{U}^{*}(\mathrm{x})$ is an artifact of the incorrect assumption about w.

Figure 2 shows that configural weighting provides a distinct interpretation of "risk aversion" from the interpretation of expected utility theory, because even when $\mathrm{u}(\mathrm{x})$ is a linear function of $\mathrm{x}$, if $\mathrm{w}<0$, the subject can prefer the expected value of a gamble to the risky gamble itself. In configural-weight theory, the subject could be characterized as "risk averse" or "risk seeking" as the value of w varies from negative to positive, respectively. In this theory, the $\mathrm{u}(\mathrm{x})$ function represents a psychophysical function that characterizes the subjective value of money, apart from risk. Returning to the example in Figure 1, if a subject equates the gamble ( $\$ 96, .5, \$ 0$ ) to $\$ 24$, configural-weight theory could explain the result with a linear utility function, $\mathrm{u}(\mathrm{x})=\mathrm{x}$, if $\mathrm{w}=-.25$.

Consideration of such examples and the relations in Figure 2 reveals that it will be difficult on the basis of a single investigation to test between the SEU and configural-weight theories, since the estimation of the $\mathrm{u}(\mathrm{x})$ function and the parameter $\mathrm{w}$ can trade-off in describing the same phenomena. However, with proper designs and constraints, configural weighting can be tested against nonconfigural models such as SEU (Birnbaum, 1973; 1974; 1982; Birnbaum \& Stegner, 1979; Birnbaum \& Sutton, in press). In particular, the present research attempts to manipulate w by changing the subject's point of view.

\section{$\underline{\text { Point of View }}$}

In the present study, judges were asked to evaluate lotteries from different viewpoints. In the buyer's point of view, judges were asked to state the highest price that a buyer should pay to purchase the opportunity to play a gamble. In the seller's point of view, they were asked to judge the lowest price that a seller should accept to give up the gamble, rather than to play it. A neutral point of view asked for a "fair price" for the buyer to pay the seller. 
Buyer's and seller's judgments of value of gambles have been employed by Coombs, Bezembinder \& Goode (1967) and by Lichtenstein \& Slovic (1971), to show the generality of other results to the two kinds of judgments, and they have been of interest to economists, who view the discrepancy between these judgments as contrary to economic theory (Knetsch \& Sinden, 1984; Harless, 1989).

According to economic theory, buyer's and seller's prices are not expected to be equal, except under special circumstances (Raiffa, 1968), because buyers and sellers can reasonably be theorized to be working from different levels of wealth on the utility function. However, the difference between buyers' and sellers' prices is too large to be explained by this "income effect", as noted for example by Knetsch and Sinden (1984), who ascertained willingness to buy or sell lottery tickets when either money or a ticket was given to the subjects and they were given the opportunity to exchange. Since their subjects were randomly assigned to receive money or the ticket, income levels should have been equivalent, hence the proportion of subjects who preferred the money or ticket should have been independent of which one had been given initially. Instead, subjects were reluctant to exchange, resulting in higher selling than buying prices.

Point of view as an experimental manipulation could in principle affect either the configural weight, $\mathrm{w}$, the utility function, $\mathrm{u}(\mathrm{x})$, or both. According to utility theory, point of view should only affect the utilities, and even that effect can be represented as a translation in the outcomes between buyer's and seller’s points of view (see Harless, 1989).

Birnbaum and Stegner (1979, Experiment 5) asked subjects to judge value from the buyer's, seller's, or neutral's point of view. They found that the rank order of judgments was systematically changed. Their analysis allowed weights and utilities of estimates to depend on the bias and expertise of the sources of information and also on the relationship between the source's bias and the judge's point of view. Among other findings, Birnbaum and Stegner (1979) concluded that the judge's point of view affected the configural weight, and the change in configural weighting explained the changes in rank order, as depicted in Figure 2. 


\section{Extensions and Special Cases of Configural Weighting}

Configural-weight theory permits a different w for each value of probability. For gambles between two positive outcomes, with probability $\mathrm{p}$ to win $\mathrm{x}$, the model can be rewritten as follows:

when $\mathrm{u}(\mathrm{x})<\mathrm{u}(\mathrm{y})$,

$$
\mathrm{U}(\mathrm{xpy})=\mathrm{S}_{\mathrm{L}}(\mathrm{p}) \mathrm{u}(\mathrm{x})+\left(1-\mathrm{S}_{\mathrm{L}}(\mathrm{p})\right) \mathrm{u}(\mathrm{y})
$$

when $\mathrm{u}(\mathrm{x})=\mathrm{u}(\mathrm{y})$,

$$
\mathrm{U}(\mathrm{xpy})=\mathrm{u}(\mathrm{x}) \text {; }
$$

and when $\mathrm{u}(\mathrm{x})>\mathrm{u}(\mathrm{y})$,

$$
\mathrm{U}(\mathrm{xpy})=\mathrm{S}_{\mathrm{L}}(1-\mathrm{p}) \mathrm{u}(\mathrm{y})+\left(1-\mathrm{S}_{\mathrm{L}}(1-\mathrm{p})\right) \mathrm{u}(\mathrm{x}) .
$$

where $x$ is received with probability $p$, and y is received with probability 1-p; $S_{L}(p)$ is the weight of the lower-valued outcome when $\mathrm{u}(\mathrm{x})<\mathrm{u}(\mathrm{y})$ and $\mathrm{S}_{\mathrm{L}}(1-\mathrm{p})$ is the weight of the lowervalued outcome when $\mathrm{u}(\mathrm{x})>\mathrm{u}(\mathrm{y})$. Expression 3 assumes that the weights sum to one but does not require (nor will it be the case) that $S_{L}(1-p)=1-S_{L}(p)$.

In the present paper, different weights will also be estimated for the case where $\mathrm{x}=0$ vs. the case where $x>0$. T. Anderson \& Birnbaum (1976) applied a model in which neutral-valued stimulus components receive less weight than components that are either positive or negative. If there are different weighting functions for these two cases (zero vs. nonzero), then the model may predict violations of monotonicity (Birnbaum \& Sutton, in press; Mellers, Weiss, \& Birnbaum, in press).

If point of view affects these configural weighting functions, then there could be a different $\mathrm{S}_{\mathrm{L}}$ function for each point of view, $\mathrm{S}_{\mathrm{VL}}(\mathrm{p})$. Configural weighting theory can be rationalized and simplified by the assumption that subjects act as if they were minimizing an asymmetric loss function whose asymmetry is affected by the point of view (Birnbaum, 1987). This rationalization leads to the following expression:

$$
\mathrm{S}_{\mathrm{VL}}(\mathrm{p})=\mathrm{a}_{\mathrm{V}} \mathrm{S}(\mathrm{p}) /\left[\mathrm{a}_{\mathrm{V}} \mathrm{S}(\mathrm{p})+\left(1-\mathrm{a}_{\mathrm{V}}\right)(1-\mathrm{S}(\mathrm{p}))\right]
$$


where $a_{V}$ is the effect of point of view on the weight of the lower-valued outcome, and $S(p)$ is a function of probability. Equation 4 simplifies Expression 3 so that point of view is represented by a single parameter, rather than an entire function.

For comparison with Equation 2 and Figure 2, when $\mathrm{S}(\mathrm{p})=.5, \mathrm{a}_{\mathrm{V}}=.5-\mathrm{w}$; hence, a value of $\mathrm{a}_{\mathrm{V}}=.25$ corresponds to $\mathrm{w}=.25 ; \mathrm{a}_{\mathrm{V}}=.75$ corresponds to $\mathrm{w}=-.25$. Derivation of Expression 4 from the loss function rationale is explained in the next section.

\section{Loss Function Rationale for Configural Weighting}

Suppose it were desired to select a value t so as to minimize the expected squared deviation between $t$ and a set of values, $x_{j}$, which occur with probabilities, $\mathrm{p}\left(\mathrm{x}_{\mathrm{j}}\right)$. The loss function can be written:

$$
\mathrm{L}(\mathrm{t})=\Sigma\left(\mathrm{x}_{\mathrm{j}}-\mathrm{t}\right)^{2} \mathrm{p}\left(\mathrm{x}_{\mathrm{j}}\right)
$$

where $\Sigma \mathrm{p}\left(\mathrm{x}_{\mathrm{j}}\right)=1$. By taking the derivative with respect to t, setting it to zero, and checking the sign of the second derivative, it can be shown that the minimum value occurs when $t$ is chosen as follows:

$$
\mathrm{t}=\Sigma \mathrm{p}\left(\mathrm{x}_{\mathrm{j}}\right) \mathrm{x}_{\mathrm{j}}
$$

Hence, choosing t as the expected value minimizes Expression 5. The expected value (the mean) is the point where the probability distribution balances, and as shown above, it is the value that minimizes the expectation of squared deviations.

If it were desired to minimize squared deviations in the utilities, expected utility is the solution. Furthermore, if the weights were chosen as $s\left(\mathrm{p}\left(\mathrm{x}_{\mathrm{j}}\right)\right)$, then SEU theory would be derived. These derivations make use of loss functions that are symmetric, because a squared deviation depends only on the absolute deviation and not its sign. Even after transformation to utilities, the loss function would be symmetric with respect to utilities.

Now, suppose that errors, or deviations cause asymmetric losses. For example, when estimating how much food to purchase for a party, the psychological costs of purchasing too much (having leftovers and waste) versus purchasing too little (and leaving guests underfed) may not be equal. The concept of an asymmetric loss function is similar to the analysis of 
payoffs in signal detection theory and to some of the intuitions motivating regret theory (Loomes \& Sugden, 1982). The buyer's and seller’s points of view presumably induce different asymmetric concerns for over- or under-estimating value. For example, when instructed to estimate the highest price a buyer should pay, the judge considers it a costly error to set too high a price (the buyer would suffer a loss), but a less costly error to offer too little (violating the instruction to judge the highest price).

Figure 3 illustrates a case of asymmetric losses, which are specified as follows:

$$
\begin{aligned}
\mathrm{L}(\mathrm{t}) & =\mathrm{a}(\mathrm{x}-\mathrm{t})^{2}, & & \text { if } \mathrm{t} \geq \mathrm{x} \\
& =(1-\mathrm{a})(\mathrm{x}-\mathrm{t})^{2}, & & \text { if } \mathrm{t}<\mathrm{x} .
\end{aligned}
$$

Suppose there are two values, $\mathrm{x}_{1}$ and $\mathrm{x}_{2}$, which occur with probability $\mathrm{p}$ and 1-p. (For example, $\mathrm{x}$ might be the amount of food required for a party: $\mathrm{x}_{1}$ if Bob doesn’t show up and $\mathrm{x}_{2}$ if he does). The weights a and 1-a represent the relative costs of over- or underestimating (for example, a > 1 - a, if it is more important not to waste food than to leave the guests wanting more; otherwise, $\mathrm{a}<1-\mathrm{a})$. Taking the derivative of the expected loss and setting it to zero, we have for $\mathrm{x}_{1}<\mathrm{t}<\mathrm{x}_{2}$ :

$$
L^{\prime}(t)=p a\left(x_{1}-t\right)+(1-p)(1-a)\left(x_{2}-t\right)=0
$$

therefore,

$$
\mathrm{t}=\left[\mathrm{pax}_{1}+(1-\mathrm{p})(1-\mathrm{a}) \mathrm{x}_{2}\right] /[\mathrm{pa}+(1-\mathrm{p})(1-\mathrm{a})]
$$

Hence, $\mathrm{t}$ is a configurally-weighted average of $\mathrm{x}_{1}$ and $\mathrm{x}_{2}$. Equation 4 follows from Expression 6, substituting $\mathrm{u}(\mathrm{x})$ for $\mathrm{x}$; $\mathrm{S}(\mathrm{p})$ for $\mathrm{p}$; and av for a. The example in Figure 3 illustrates the situation for two equally likely values, $\mathrm{x}_{1}=100$ and $\mathrm{x}_{2}=200$, with $\mathrm{a}=.75$ (corresponding to $\mathrm{w}=-.25$ ); the solution, $\mathrm{t}=125$, is shown in the figure.

Insert Fig. 3 about here

Figure 4 shows the relationship between $\mathrm{S}_{\mathrm{VL}}(\mathrm{p})$ and $\mathrm{S}(\mathrm{p})$ as point of view, $\mathrm{a}_{\mathrm{V}}$, is varied. This figure illustrates the implication of Equation 4 for the relationship between 
weight of probability and point of view. As a first reaction, one might have wondered whether the introduction of loss functions is an unnecessarily complex rationale for configural weighting, except that this reasoning leads to the simplification of Equation 4, which has the testable implication indicated in Figure 4. This theoretical interpretation of configural weighting also suggests that manipulations which asymmetrically affect the costs of errors should have predictable effects on configural weights. This interpretation offers an organizing principle for understanding the effect of point of view and other motivational factors.

Insert Fig. 4 about here

\section{Purposes of Present Research}

The present paper explores three implications of configural-weight theory that could pose difficulties for SEU theory. First, the investigation will test whether point of view produces a change in rank order of the gambles, of the specific form predicted by the theory that point of view affects the configural weight of the higher or lower amounts (Figure 2).

Second, the experiments test a particular implication of configural-weight theory for an anticipated violation of branch independence. Branch independence is the property that if two gambles have a branch (probability and outcome) that is identical, then the (common) branch should have no effect on the ordering produced by other branches. Branch independence is implied by Equation 1, because if two gambles have a common branch, the product of $\mathrm{s}(\mathrm{p}) \mathrm{u}(\mathrm{x})$ for that branch can be subtracted off from both gambles. However, configural-weight theory allows violations, because the weight of an outcome depends on its position among the outcomes; the same outcome could have different weightings in different gambles, depending on the other outcomes in the gamble.

Third, these experiment investigate a possible violation of monotonicity that would be implied by configural-weight theory if the weight of an outcome depends on its value. 
Monotonicity is the property that if a $>b, \mathrm{U}(\mathrm{apz})>\mathrm{U}(\mathrm{bpz})$, for any $\mathrm{p}$ and $\mathrm{z}$. This property, sometimes called dominance, is required by Equation 1. Some configural theories, such as dual bilinear utility theory (Luce \& Narens, 1985; Luce, 1986) and rank- and signdependent utility theory (Luce \& Fishburn, in press) were developed using the assumption of monotonicity. However, less restrictive configural- weight models devised to account for judgment results in other domains do not require monotonicity (T. Anderson \& Birnbaum, 1976; Birnbaum \& Sutton, in press).

\section{Method}

The subject's task was to judge the values of lotteries from the buyer's, neutral's, and seller's points of view. For example, consider a 50-50 bet to win either $\$ 96$ or $\$ 0$ (zero). What is the most you would advise a buyer to pay to play this gamble? What is the least a seller should accept to sell the chance to play the gamble? What is the fair price? Two experiments used the same stimulus format and instructions, but different subjects and different designs to construct the lotteries.

\section{Stimuli}

The stimuli in both experiments were presented using the format in the following example:

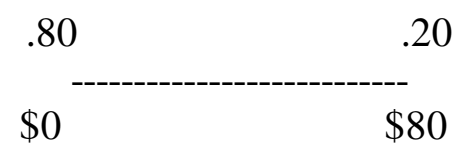

which represented a lottery with a .20 chance to win $\$ 80$, and a .80 chance to win $\$ 0$. The gambles were described as lotteries in which equally likely slips of paper would be drawn at random, and the amount specified on the slip would be paid to the player. Probability was characterized as the number of slips per 100 that would yield each amount to win. $\underline{\text { Instructions }}$

The instructions read (in part) as follows:

"In the buyer's point of view, imagine that you are deciding the most that a buyer should pay to buy the chance to play the lottery. The buyer exchanges money for the chance 
to play the lottery. If the lottery pays off, the buyer can profit; if not, the buyer can lose the difference between the amount won and the price of the lottery.... the buyer wants to pay as little as possible and to have as a good a chance of winning good payoffs as possible. The buyer will be upset with you if you advise the buyer to pay for gambles that lose too much money. Remember, you are asked to advise the buyer the most he or she should be willing to pay to get to play the lottery.”

“In the seller's point of view, ...you are deciding, what is the least that a seller should accept to sell the lottery. The seller receives money and gives up the chance to play the lottery. Thus, if the lottery pays off, the seller would have been better off to have kept the lottery than to have sold it, but if the lottery doesn't pay off, (or pays only a little) the seller profits by selling... The seller wants to receive as much as possible for each gamble. The seller will be upset if you advise selling a gamble for a low price that pays off the buyer a lot of money. Remember, you are asked to advise the seller concerning the least the seller should accept to sell the lottery, rather than play it ...”

"In the neutral point of view, imagine that you are neither the buyer nor seller of the lottery, but rather you are a neutral judge who will decide the fair price or "true value" of the lottery (that the buyer could pay the seller) so that neither buyer nor seller has received any advantage from your judgment...”

\section{Design of Experiment 1}

The stimuli were constructed from two factorial subdesigns. The first sub-design generated 60 distinct, two-outcome gambles, with a probability $\mathrm{p}_{\mathrm{x}}$ to win $\mathrm{x}$ and a probability of $1-\mathrm{p}_{\mathrm{x}}$ to win $\mathrm{y}$.

There were 3 values of $\mathrm{p}_{\mathrm{x}}\left(.8, .5\right.$, and .4 ; hence $1-\mathrm{p}_{\mathrm{x}}=.2$, .5, and .6, respectively). There were 4 values of $x(\$ 8, \$ 16, \$ 32$, and $\$ 64)$ and 5 values of y $(\$ 0, \$ 10, \$ 20, \$ 40$, and $\$ 80)$. This Probability by Amount x by Amount y design produced $3 \times 4 \times 5=60$ cells.

The second subdesign of Experiment 1 generated 10 distinct, three outcome gambles from a $2 \times 5$, Amount $x$ by Amount y factorial, in which there was a .10 chance to receive 
either $\$ 5$ or $\$ 100$, a .4 chance to $\$ 16$, and a .5 chance to win either $\$ 0, \$ 10, \$ 20, \$ 40$, or $\$ 80$. (Note that gambles in this design include a .5 chance to win y as in the first subdesign, but the remaining .5 probability is divided among two outcomes).

Design of Experiment 2

The stimuli, instructions, and procedures of Experiment 2 were identical to those of Experiment 1. Only the design (construction of the experimental trials) and the subjects differed. The major subdesign was a $5 \times 9$ factorial, constructed from pairs of outcomes: (\$24, p, \$0), (\$72, p, \$0), (\$96, p, \$0), (\$72, p, \$24), (\$96, p, \$24) combined with 9 levels of probability of winning the higher amount in each pair (.05, .1, .2, .4, .5, .6, .8, .9, .95). In addition, the pair of (\$96, p, \$72) was combined with probability levels of .5 and .8 of winning the higher amount. Finally, 16 additional trials were constructed from successive amounts at $\$ 6$ intervals, with a probability of .5: $(\$ 6, .5, \$ 0),(\$ 12, .5, \$ 6), \ldots,(\$ 96, .5$, $\$ 90)$.

\section{Procedure}

Instructions, warm-up trials, and randomly ordered experimental trials were printed in booklets. An equal number of subjects received each of the six possible orders of points of view.

In Experiment 1, there were 11 warm-ups preceding the 70 experimental lotteries for each point of view (33 warm-ups and 210 experimental, 243 in all). Experiment 2 had 63 experimental lotteries and 11 practice lotteries in each point of view (33 warm-ups and 189 experimental), giving a total of 222 trials. Each experiment required about 2 hours.

\section{$\underline{\text { Subjects }}$}

The subjects were 133 California State University, Fullerton undergraduates who participated for credit in Introductory Psychology. There were 80 and 53 different subjects in Experiments 1 and 2, respectively. 


\section{Results}

\section{$\underline{\text { Point of View }}$}

Figure 5 shows results for the two-outcome subdesign in Experiment 1. Mean judgments for the three points of view (buyer's, neutral's, and seller's) are shown in the left, middle, and right columns of panels, respectively. Judged prices are plotted in each panel as a function of Amount $y$, with a separate curve for each level of $x(x=\$ 8, \$ 16$, $\$ 32$, or $\$ 64)$. Filled circles represent mean judgments; curves in Figures 5-9 show predictions of configural-weight theory, which are discussed in the section on model fitting.

The slopes of the curves in Figure 5 represent the effects of Amount y; the vertical spreads between the curves represent the effects of Amount x. The slopes in the upper panels are smallest, and the vertical spreads are the greatest, where $\mathrm{p}(\mathrm{y})=.2$ and $\mathrm{p}(\mathrm{x})=.8$. Slopes and vertical spreads are intermediate in the center row of panels, where the outcomes are equally probable. Slopes are greatest and vertical spreads are the least in the lower row of panels, where $\mathrm{p}(\mathrm{y})=.6$ and $\mathrm{p}(\mathrm{x})=.4$. These variations in the slopes of the curves and the vertical spreads between curves are characteristic of both the data and the theory curves.

\section{Insert Figure 5 about here}

Figure 5 also shows that the average height of the judgments and relative divergence of the curves change as a function of point of view. For the buyer's point of view, judgments are lowest and the data in each panel diverge to the right (vertical spreads between the curves increase from left to right); in the seller's point of view, judgments are highest and the curves are more nearly parallel.

The rank order of the gambles also changes in the different points of view. For example, a 50-50 gamble to win $\$ 8$ or $\$ 80$ is judged higher than a 50-50 gamble to win 
either $\$ 32$ or $\$ 40$ from the seller’s point of view, but the order is opposite in the buyer’s point of view.

Analysis of variance of the data displayed in Figure 5 indicated that 14 of the 15 main effects and interactions of point of view, amount $\mathrm{x}$, amount $\mathrm{y}$, and probability were statistically significant ("significant" denotes $\mathrm{p}<.01$, throughout this paper). For example, the main effect of point of view yielded $F(2,158)=52.01$; the three-way interaction of point of view by amount $\mathrm{x}$ by amount y yielded $\mathrm{F}(24,1896)=12.34$. The nonsignificant effect was the two-way interaction between point of view and probability, $\mathrm{F}(4,316)=1.38$.

Figure 6 shows mean judgments from Experiment 2, with a separate panel for each point of view. Mean judgments of value are plotted as a function of the probability of winning $y$ in gambles of the form, $(y, p, \$ 0)$, with a separate curve for each value of $y(y=$ $\$ 24, \$ 72$, or $\$ 96)$. As in the other figures, symbols depict data and lines show predictions of configural-weight theory. All four main effects involving point of view, lower amount, higher amount, and probability were statistically significant, as were 5 of the 6 two-way interactions; the two-way interaction between point of view and lower amount was nonsignificant, as were all of the higher order interactions. For example, $F(2,104)=54.39$ for point of view. There is also a "glitch" in four of the nine sets of data, in which the means decrease as the probability is increased from .5 to .6; it is unclear whether or not these represent a replicable trend.

Insert Figure 6 about here

The effect of point of view in Experiment 2 is highlighted in Figure 7. The left portion of Figure 7 shows mean judgments of gambles between $\$ 0$ and $\$ 96$, as a function of the probability of winning $\$ 96$, with a separate type of symbol for each viewpoint. Seller’s means (circles) are always highest and buyer's means (diamonds) are always lowest. Narrow-range, 50-50 gambles are plotted against point of view in the same figure for 
comparison. This figure shows that the effect of viewpoint is greater for the wide-range gambles.

The diagonal, straight line in Figure 7 shows expected value for the $(\$ 96, p, \$ 0)$ gambles. Although subjects in the neutral and buyer's viewpoints tend to evaluate most gambles below their expected values, note that low probability gambles are judged higher than their expected values in all three points of view. In expected utility theory, such findings have suggested different "risk seeking" or "risk averse" utility functions for different levels of probability (Becker \& Sarin, 1987). As shown by the predictions, configuralweight theory handles these results with a single utility function.

Insert Figure 7 about here

\section{Branch Independence}

Experiment 1 revealed violations of branch independence. According to any model that assumes independence (for example, if products of terms involving probabilities and outcomes are added, as in Equation 1), then the order of gambles should be the same when a branch (probability and outcome) is held constant. However, in all three points of view, the mean judgments of the gambles have the following orders:

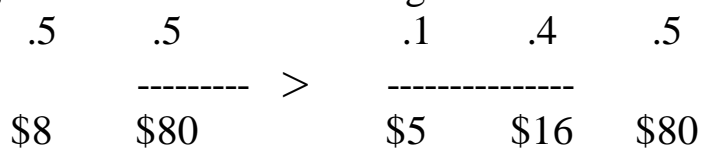

however,

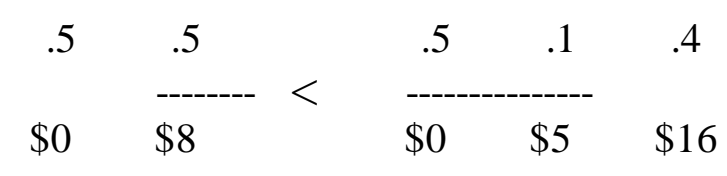

In the first comparison, the .5 chance to win $\$ 80$ is the same in both lotteries; in the second comparison, the .5 chance to win $\$ 0$ is the same in both lotteries. Therefore, the order of the other branches should have been the same, according to branch independence. 
Instead, the .5 chance to win $\$ 8$ is better than .1 to win $\$ 5$ and .4 to win $\$ 16$ in the first comparison, but the order is reversed in the second.

The configural-weight model can tolerate such otherwise perplexing results, because the weight of a branch depends on the rank of its outcome among the other outcomes. For example, suppose that $50 \%$ of the weight of higher outcomes is transferred to the lowest outcome. Assuming for simplicity that $\mathrm{S}(\mathrm{p})=\mathrm{p}$ and $\mathrm{u}(\mathrm{x})=\mathrm{x}$, this configural theory would then accommodate these relations, as in the following calculations:

$$
.75(8)+.25(80) \quad>\quad .55(5)+.2(16)+.25(80)
$$

for the first pair of gambles, and

$$
.75(0)+.25(8) \quad<\quad .75(0)+.05(5)+.2(16)
$$

for the second pair of gambles. This example illustrates how configural weighting could explain violations of branch independence.

Violations are shown in greater detail in Figure 8, which plots mean judgments as a function of the amount of the common branch (y with probability .5), with separate curves for the two- and three- outcome gambles (solid symbols and lines indicate gambles with .5 chance to win $\$ 8$, otherwise y; open circles and dashed lines indicate gambles with .4 chance to win $\$ 5$, .1 chance to win $\$ 16$, otherwise y). The crossovers of the data indicate violations of branch independence. The crossovers of the lines show that configural-weight theory can also cross in the same direction, although the predictions cross below $\$ 20$, whereas the data cross above \$20 in each panel. Similar results have been observed with ratings of the attractiveness and risk of gambles (Weber, Anderson, \& Birnbaum, in press).

The rank order of the open and solid symbols at each level of amount is the same in all three panels. All six main effects and interactions associated with the three-outcome designs (depicted in Figure 8) were also statistically significant. For example, the main effect of point of view yielded $F(2,158)=55.77$. 
Insert Figure 8 about here

\section{$\underline{\text { Monotonicity Violations }}$}

In Figure 9, mean judgments are plotted as a function of the probability of winning \$96, using open circles when the smaller amount was $\$ 0$ and filled circles when the smaller amount was $\$ 24$. Predictions of the configural-weight theory are shown as lines. Each panel represents a different point of view. Monotonicity requires that the curves shouldn't cross (it should be better to have a chance to get $\$ 24$ than the same chance at $\$ 0$, when everything else is the same) so the filled circles should be above the open circles in all cases.

Insert Figure 9 about here

Instead, Figure 9 reveals violations of monotonicity in all three points of view. For example, the mean judged value of a .95 chance to win $\$ 96$ and .05 to win $\$ 0$ is higher than the judgment of a .95 chance to win $\$ 96$ and a .05 chance to $\$ 24$. The percentages of subjects in each point of view who violated dominance for these gambles are shown in each panel of Figure 9.

Monotonicity implies that all of the filled circles should fall above the open circles in each panel of Figure 9, contrary to the orders for the last three pairs of points within each panel. According to the null hypothesis that the curves actually coincide at those three points (the limiting case of monotonicity), and the pairwise orders are the result of a fiftyfifty chance at each point, the probability would be $(1 / 2)^{9}$; therefore, it is unlikely that nine violations would fall in such a pattern by chance. A similar pattern was also obtained with gambles between $\$ 0$ and $\$ 72$, compared with gambles between $\$ 24$ and $\$ 72$. The gamble $(\$ 72, .95, \$ 0)$ received a higher mean judgment than $(\$ 72, .95, \$ 24)$ in all three points of view.

These results violate the assumption of monotonicity that underlies SEU theory and also certain rank-and sign-dependent theories (Luce \& Fishburn, in press), but they can be 
described by the more general configural-weight theory, if weights are permitted to depend on value as well as rank. The theoretical curves in Figure 9 show that the configural-weight model can describe violations of monotonicity. Additional details of the model are described in the next section.

\section{Model Fitting}

The models were fit to the 399 mean judgments of Experiments 1 and 2 by means of a special computer program, written to find parameter estimates that would minimize a weighted sum of squared deviations between the data and predictions. In each experiment, the sum of squared residuals was divided by the sum of squared deviations about the mean. The index minimized was the sum of proportions of residual variance in the two experiments. Chandler's (1969) subroutine, STEPIT, was used to facilitate the minimizations.

Because the overt response, $\mathrm{R}$, is in money, a transformation between subjective utility ( $\Psi$ ) and response was estimated. It is tempting to constrain this function to be the inverse of the utility function; however, these functions were permitted to differ, to allow for possible judgmental effects. This transformation was approximated as a power function, $\mathrm{R}=$ $\Psi \mathrm{d}$, where $\mathrm{R}$ is the response and $\mathrm{d}$ is the exponent. In different versions of the program, the values of $\Psi$ are given either by SEU theory (Equation 1) or by configural-weight theory (Equation 3), combined with the simplified theory of point of view (Equation 4).

\section{Fit of Configural-Weight Theory}

Each point of view was permitted a different value of $a_{V}$. Combining Expressions 3 and 4 , the equation for gambles with $\mathrm{p}_{\mathrm{x}}$ to win $\mathrm{x}$, otherwise $\mathrm{y}$, when $0<\mathrm{x}<\mathrm{y}$ is as follows:

$$
\Psi=\begin{gathered}
\mathrm{a}_{\mathrm{V}} \mathrm{S}\left(\mathrm{p}_{\mathrm{x}}\right) \mathrm{u}(\mathrm{x})+\left(1-\mathrm{a}_{\mathrm{V}}\right)\left(1-\mathrm{S}\left(\mathrm{p}_{\mathrm{x}}\right)\right) \mathrm{u}(\mathrm{y}) \\
\mathrm{a}_{\mathrm{V}} \mathrm{S}\left(\mathrm{p}_{\mathrm{x}}\right)+\left(1-\mathrm{a}_{\mathrm{V}}\right)\left(1-\mathrm{S}\left(\mathrm{p}_{\mathrm{x}}\right)\right)
\end{gathered}
$$


Three-outcome gambles were treated as one lower-valued outcome combined with two higher-valued ones. For three outcomes, $0<\mathrm{x}<\mathrm{y}<\mathrm{z}$, with probabilities, $\mathrm{p}_{\mathrm{x}}, \mathrm{p}_{\mathrm{y}}$, and $\mathrm{p}_{\mathrm{z}}=1$ - $\mathrm{p}_{\mathrm{x}}-\mathrm{p}_{\mathrm{y}}$, respectively, the equation is as follows:

$$
\Psi=\begin{gathered}
a_{V} S\left(p_{x}\right) u(x)+\left(1-a_{V}\right)\left(1-S\left(1-p_{y}\right)\right) u(y)+\left(1-a_{V}\right)\left(1-S\left(1-p_{z}\right)\right) u(z) \\
a_{V} S\left(p_{x}\right)+\left(1-a_{V}\right)\left(1-S\left(1-p_{y}\right)\right)+\left(1-a_{V}\right)\left(1-S\left(1-p_{z}\right)\right)
\end{gathered}
$$

When $\mathrm{x}=0, \mathrm{~S}_{0}(\mathrm{p})$ replaces $\mathrm{S}(\mathrm{p})$ throughout Equations 7 and 8 .

The predictions shown in the figures were calculated from this configural-weight theory, which left only $0.69 \%$ and $0.66 \%$ of the variance in the residuals in Experiments 1 and 2, respectively. A separate value of $\mathrm{u}(\mathrm{x})$ was estimated for each of the 27 values of $\mathrm{x}$, and this estimated utility function is shown in Figure 10. The estimated values of $\mathrm{u}(\mathrm{x})$ were within $\$ 2$ of their physical value in all cases, except $u(\$ 0)$ was estimated to be 2.89 . The exponent of the power function representing the judgment function was near one, $d=.99$.

\section{Insert Figure 10 about here}

Because the estimated utilities are so close to their physical values, the model was then fit with the assumption that $\mathrm{u}(\mathrm{x})=\mathrm{x}$, with a linear judgment function, $\mathrm{R}=.95 \Psi+1.35$. The deviations of fit increased only slightly, to $0.80 \%$ and $0.80 \%$ in the two experiments. Correlations between this simplified theory, which requires 27 fewer parameters, and mean judgments are .996 and .996 for Experiments 1 and 2, respectively.

The configural weighting parameter, av, was fixed to .5 in the seller's point of view. Therefore, the estimated weights, $S(p)$ and $S_{0}(p)$, shown in Figure 11, are the weights of the lower outcomes from the seller's point of view. Figure 11 shows that $\mathrm{S}_{0}(\mathrm{p})<\mathrm{S}$ (p) for small values of p. This pattern explains the violations of monotonicity shown in Figure 9. For example, $\mathrm{S}(.05)=.33$ and $\mathrm{S}_{0}(.05)=.18$; therefore, the calculated value of $\Psi$ for 
$(\$ 96, .95, \$ 0)$ in the seller's point of view is $96(1-.18)+0(.18)=79$, which is greater than $\Psi$ for $(\$ 96, .95, \$ 24)$, which is $96(1-.33)+24(.33)=72$.

\section{Insert Figure 11 about here}

For buyer's and neutral's points of view, the estimates of av are .71, and .60, respectively. Substituting these values in Equation 4, with the estimate of $S(.5)=.53$, the weights of the lower vs. higher of two equally likely, positive outcomes are .73 vs. .27, .63 vs. .37, and .53 vs. .47 in the buyer's, neutral's, and seller's points of view, respectively. In relation to Equation 2 and Figure 2, these values correspond to $\mathrm{w}=-.23,-.13$, and -.03 , respectively. Thus, the model predicts that the 50-50 gamble to win either $\$ 8$ or $\$ 80$ should be worth $\$ 27$, \$34, and \$41 from the buyer’s, neutral’s, and seller’s viewpoints, respectively, close to the empirical values in Figure 5 (right-most point on the lowest curve of the center row of panels).

A more complex configural-weight model was fit which allowed a different $S_{V L}(p)$ function in each point of view, but the improvement of fit was trivial. The estimated weights were very similar to those predicted by Equation 4. Assessment of Equation 4 is facilitated in Figure 7, which displays the accuracy of the one-parameter representation of point of view. The deviations do not appear systematic. Similarly, allowing different utility functions for different points of view (as well as different configural weights) also improved the fit by only a trivial margin.

Comparisons of theory (lines) and data (symbols) in Figures 5-9 show that the configural model gives a good account of the effect of point of view in both experiments and also predicts the violations of branch independence and dominance. Therefore, the present data allow one to retain the theory that the utility function is invariant with respect to point of view, and that one can characterize point of view by a single parameter, av. Because the utility function could be approximated with a linear function, the key parameters for 
describing the present phenomena are the two functions in Figure 11 and the configural parameter, $a_{V}$.

\section{$\underline{\text { SEU Predictions }}$}

If configural-weight theory can explain the effects of point of view with different weighting functions and a single $\mathrm{u}(\mathrm{x})$ function, it might seem that perhaps Equation 1 could be extended to do as well using different $\mathrm{u}(\mathrm{x})$ functions and a single, $\mathrm{s}(\mathrm{p})$ function. Equation 1 was therefore fit with different utility functions and different output functions in each point of view, but the subjective weighting function for probability, s(p), was assumed to be nonconfigural and independent of viewpoint. In one version, there were 88 parameters, including 81 different $\mathrm{u}(\mathrm{x})$ estimates (for the 27 values of $\mathrm{x}$ in three points of view). The sum of squared discrepancies for this model was nearly three times that of the simplified configural-weight theory, which used only one fourth as many parameters.

When the $\mathrm{u}(\mathrm{x})$ functions and judgment (output) functions were constrained to be power functions, the sum of squared residuals for Equation 1 was doubled again. The exponents showed the pattern expected from configural-weight theory (Figure 2): exponents of the utility (input) function were .68, .81, and 1.00 for buyer's, seller's, and neutral's points of view, and the corresponding output exponents were estimated to be $1.40,1.19$, and .98, respectively. The products of exponents are less than 1 , which allows the model to approximate the overweighting of the lower-valued outcome in wide-range gambles, but the model systematically underpredicted small-range gambles.

Even with changing utility functions, SEU theory could not account for the violations of monotonicity and of branch independence, and its description of the point of view manipulation was less accurate than that of configural-weight theory. In sum, configural theory gives a better account of the data by assuming that weight of the lowervalued item changes in different points of view than does SEU theory, even with the assumption that the utility function changes.

\section{Discussion}


The present results show that manipulation of the judges’ point of view causes a change in the rank order of the values of lotteries. This change in rank order can be neatly summarized by the assumptions that the utility function is the same, but the configural weights depend on point of view. These conclusions are compatible with other findings (Birnbaum \& Stegner, 1979; Birnbaum \& Sutton, in press). In contrast, SEU theory does not fit data as well, even allowing different utility functions for different points of view, nor can SEU theory account for violations of branch independence (Figure 8) and monotonicity (Figure 9).

\section{Violations of Dominance and Branch Independence}

The violations of monotonicity (dominance) in Experiment 2 seem startling from a normative perspective. Why should subjects offer to pay more for gambles in which everything is the same except that one outcome has a lower value? As Luce (1986) noted, there have been few experimental tests of monotonicity, perhaps because the principle has been considered so compelling. The present interpretation explains violations of monotonicity as a consequence of the underweighting of zero-valued outcomes, illustrated in Figure 11. The next question one might ask is why zero or neutral-valued outcomes receive less weight.

The striking result in Figure 9 led to subsequent experiments that sought to identify why and under what conditions the effect occurs. Birnbaum and Sutton (in press), replicated the violations of monotonicity for buying and selling prices. In addition, they also presented the same gambles for direct choice and found that although subjects often violate monotonicity in pricing judgments, subjects rarely chose the dominated gamble $(\$ 96, .95, \$ 0)$ over the dominating gamble $(\$ 96, .95, \$ 24)$ in a direct comparison. Their finding represents yet another reversal of preference that is distinct from both the "classic" preference reversal and the changes in rank order due to manipulation of the viewpoint.

Mellers, Weiss, and Birnbaum (in press) conducted a number of variations to follow up the present violations of monotonicity, using a different format for display of probabilities 
(pie charts). They found that monotonicity can be violated with positive and negative amounts, with large and small values, and even when subjects are given cash incentives to place higher values on preferred gambles. In one condition, subjects were told that they would play one of two gambles at the end of the study. Of the two gambles, they were to play the gamble to which they had assigned the higher price in the experiment. Despite such incentives, subjects continued to violate dominance in all judgment conditions except one.

One manipulation significantly reduced the incidence of violations in Mellers et al. (in press): when only a few gambles were printed on a single page for judgment, subjects violated monotonicity less often. Apparently, this condition facilitates comparison of gambles, and makes the judgment task more similar to the direct comparison task, as in Birnbaum and Sutton (in press).

Branch independence is implied by SEU theory. In Figure 8, the effect of a .5 probability outcome is reduced when there are two other outcomes, compared to when there is only one other outcome, contrary to branch independence. The present result can be explained by configural weighting, as shown in the figure. Violations of branch independence have also been observed in ratings of the attractiveness and risk of gambles (Lynch, 1979; Weber, et al, in press). In Weber, et al, it was found that the effect of a branch is less when there are a greater number of other outcomes and also when the other outcomes have greater variance.

Configural Weighting, and Utility Measurement

A major difficulty for Expected Utility theory has been the failure of the theory to yield consistent estimates of utility. When different values of probability are used, EU theory yields different utility functions (Hershey, Kunreuther, \& Schoemaker, 1982). Furthermore, different methods for measuring utility yield different scales (Bell \& Raiffa, 1988; Edwards, von Winterfeldt, \& Moody, 1988; Galanter, 1962; Hershey \& Schoemaker, 1985; Keller, 1985; Stevens, 1966; Tversky, 1967a, 1967b; Breault, 1983; von Winterfeldt \& Edwards, 1986). Some have theorized that there are different scales for utility and value 
of money (Bell \& Raiffa, 1988); others have theorized that utility functions may be dependent on the lottery (Becker \& Sarin, 1987; Daniels \& Keller, in press). However, configural-weight theory offers the hope that it may be possible to explain these otherwise perplexing phenomena, using a single scale of utility.

For example, EU theory would use different $\mathrm{u}(\mathrm{x})$ functions to describe the finding in Figure 7 that seller's prices can be above or below expected value. For small values of p, the $\mathrm{u}(\mathrm{x})$ function would be positively accelerated ("risk seeking”) and for large values of p, the u(x) function would be negatively accelerated ("risk averse”). Even the buyer’s prices exceed expected value for $\mathrm{p}=.05$. This result is analogous to the well-known fact that even people who ordinarily seem "risk averse" will pay more than expected value for a state lottery ticket that offers a tiny chance to win a large prize. Although EU theory has struggled to explain such phenomena, configural-weight theory can handle them with the weighting functions in Figure 11, without attributing them to changing utilities.

The utility function estimated from configural-weight theory in the present study could also be used to predict the judgments in all three points of view, and it was nearly linear. Without configural weighting, the utility function inferred Equation 1 changed from nearly linear in the seller's viewpoint to concave downwards in the buyer's viewpoint.

Birnbaum and Sutton (in press) asked whether the utility function estimated from configural-weight theory could also be used to predict judgments of "ratios" and “differences” of utilities of monetary amounts, as well as the buying and selling prices of gambles involving the same amounts. They found that configural-weight theory permitted a single function $\mathrm{u}(\mathrm{x})$ to explain all four arrays of data. SEU theories, on the other hand, indicated that the utility functions for money differ from the values that reproduce riskless judgments of “ratios” and “differences.” Birnbaum and Sutton argued in favor of configural-weight theory on the basis of scale convergence, the premise that theories that can accomodate several phenomena with common measurement scales should be preferred to theories that need new measurement scales in each new situation. 


\section{Ambiguous Utilities and "Sure Things"}

Both the present results and those of Birnbaum and Sutton (in press) could be explained by the assumption that $\mathrm{u}(\mathrm{x})$ is independent of the point of view, and the change in rank order is due to a change in configural weighting. However, when utilities are ambiguous, one should expect estimated utilities to depend on viewpoint as well. When utilities are ambiguous, even "sure things" should show an effect of point of view.

In Birnbaum and Stegner (1979), judges were asked to estimate the "true" values, buyer's prices, and seller's prices of used cars, based on blue book value and estimates provided by sources who examined the car. The sources varied in both mechanical expertise and bias (friendship to the buyer or seller). For example, suppose an expert mechanic who is a friend of the seller says a used car is worth $\$ 7000$ and a friend of the buyer who is not a mechanic says a car is worth $\$ 3000$; what is the least that the seller should be willing to accept to sell it? A key difference between the present study and that of Birnbaum and Stegner (1979) is the greater ambiguity in the translation of monetary estimates in the Birnbaum and Stegner study. This greater ambiguity explains why estimated utilities in Birnbaum \& Stegner (1979) contained an additive constant that depended on the source's bias and the judge's point of view. Interpreting ambiguity as subjective variability that is known to the subject clarifies how this conclusion fits with the concept of a loss function, as in Figure 3.

Suppose it is assumed that a given value of the estimate, $\mathrm{x}$, produces a distribution of utilities for the subject. Further, suppose that this distribution is known to the subject (Birnbaum, 1972; 1974; 1983; Mellers, Richards \& Birnbaum, in press). For example, when a certain source says that a particular item is “worth $\$ 1000$ ”, the subject may have learned from experience that the item might actually sell for values between $\$ 20$ and $\$ 5000$, with some distribution. Thus, even a "sure thing," like a diamond ring, may be inherently variable and thus amenable to the loss function interpretation shown in Figure 2, applied to a subjective distribution. Therefore, what might appear to be a change in the $\mathrm{u}(\mathrm{x})$ function 
due to point of view [as in Birnbaum and Stegner, 1979, Experiment 5] could actually be the consequence of an internal distribution of values integrated by the subject.

If a single estimate of value corresponds to a distribution, it seems reasonable to allow the subject to consider her or himself also to be a source of information. Presumably, people know that their own estimates of value are fallible. Consequently, one would expect, selling prices to exceed buying prices for real goods of ambiguous value that subjects possess for exchange. For example, if subjects were given a diamond ring at the beginning of the experiment and asked to set a price to sell the ring, they would likely state a higher price than if they were asked how much they would pay to buy the same ring. Different points of view would then produce different loss functions, as in Figure 3, which when applied to the uncertainty about the value of the ring would result in different prices. The buyer is afraid of paying $\$ 1000$ for a ring that might be worth $\$ 20$, whereas the seller is afraid of selling a ring for $\$ 1000$ that might be worth $\$ 5000$. On the other hand, sure things to win monetary amounts should not vary between points of view because any ambiguity about the utility of money is perfectly correlated between the stimulus and response dimensions.

\section{Configural Weighting and Point of View}

The present treatment of point of view differs from traditional treatments of buyer's and seller’s prices (Raiffa, 1968; Harless, 1989). In the approach of this paper (as well as in Birnbaum \& Stegner, 1979), point of view is treated as a continuous variable. Presumably, buyer's, seller's, and neutral's points of view are just three values among many that could be induced by variation of the instructions. According to this approach it should be possible to produce points of view in between or more extreme than those induced by the present instructions. Furthermore, manipulations of loss functions should affect the points of view.

The present treatment of buyer's vs. seller's prices is also distinct from one recently introduced by Luce (in press, b) in the framework of rank and sign-dependent linear utility theory. In Luce's (in press, b) treatment, the buyer is assumed to interpret the task as the joint receipt of a sure loss (the price paid) with the gamble, whereas the seller interprets the 
selling price as a sure gain jointly combined with a lost gamble. Luce (in press, b) interprets prospect theory (Kahneman \& Tversky, 1979) as a special case of rank- and sign-dependent theory, but he concludes that prospect theory predicts no difference between buying and selling prices, because it does not entail the proper pattern of weighting required to explain the typical results. Prospect theory assigns the same weight to the lowest negative value and the highest positive value if they are equally probable. In Luce’s (in press, b) approach, rank and sign-dependent weighting is constant (more weight is consistently assigned worse outcomes), but buying and selling prices induce different descrete patterns of losses and gains. The theory does not address other viewpoints. In contrast, the present approach assumes that configural weighting changes continuously with factors that affect the point of view.

Configural weighting can be viewed as a consequence of axioms that have a rational character (Luce, 1986), as a consequence of the judge acting as if he/she is minimizing an asymmetric loss function (Birnbaum, 1987), or as a descriptive equation that can explain why the effect of one piece of information depends on the value with which it is paired (Birnbaum, 1974; Birnbaum \& Stegner, 1979). In the same way that truth of a deduced conclusion does not prove the truth of the premises, the merit of configural weighting as a device to account for the present data does not prove, for example, that subjects are minimizing asymmetric loss functions. Theoretical rationalizations acquire their status from their power to predict to new situations and to provide a coherent account of what would otherwise be unrelated phenomena. The concepts of configural weighting as a reflection of point of view seems to provide an attractive way to connect other phenomena in psychology of judgment (Birnbaum, 1982).

In judgments of the morality of persons who have done different deeds, the likeableness of persons described by adjectives, or the value of gambles characterized by amounts to win, the worst deed, adjective, or outcome receives greatest weight (Birnbaum, 
1972; 1973; 1974; Birnbaum \& Jou, 1990; Birnbaum \& Mellers, 1983). All of these situations involve a buyer's point of view, and the buyer needs to beware.

When students are asked to judge the grades that should be assigned to other students, they place equal or even higher weight on the lower score (Mellers \& Birnbaum, 1983). However, when students are asked how exams should be combined to determine their own grades in a class, they often suggest that their lowest exam score should be forgotten, as if they are in the seller's point of view.

When people consider how their own morality will be judged, they hope that their sins will be forgiven, but when they judge the morality of others, the worst deed overwhelms even a large number of good deeds (Birnbaum, 1973; Riskey \& Birnbaum, 1974). These findings are all compatible with the idea that point of view is the consequence of different patterns of losses which presumably change the configural weights of higher-and lowervalued outcomes.

\section{Preference Reversals}

The changes in rank order due to point of view (both experiments), the violations of branch independence (Experiment 1), and the violations of dominance (Experiment 2) represent three new "preference reversal” effects that are not addressed by recent theories offered to explain other preference reversals (Tversky, Sattath, \& Slovic, 1988; Goldstein \& Einhorn, 1987; Mellers, Ordoñez, \& Birnbaum, in press). Those theories attempt to explain why some gambles are rated as worth more money but are less preferred in choice or rating tasks.

The classic example of preference reversals, discussed by Lichtenstein and Slovic (1971), Slovic and Lichtenstein (1983), Goldstein and Einhorn (1987), Grether and Plott (1979), and Tversky, et al (1988), involves contrasts between pricing judgments and direct choices in the evaluation of gambles with equal expected value. Subjects tend to place a higher price on small probabilities to win large amounts, but they tend to prefer the higher probability gamble when given a direct choice. 
Such reversals have been interpreted as dependent on the tradeoff of probabilities and amounts (Tversky, et al, 1988; Slovic, 1967; Slovic \& Lichtenstein, 1983). Mellers, Ordoñez, \& Birnbaum (in press) found that the relationship between bids and ratings of the attractiveness of gambles could be described by a change in processing strategy, rather than a change in weighting in the different tasks. They concluded that bids are a multiplicative function of probability and amount, whereas ratings are an additive function of probability and amount.

Bostic, Herrnstein, \& Luce (1990) found that the classic preference reversals were reduced when direct choices are compared with choice-based certainty equivalents, rather than judged equivalents. It might seem, therefore, that it is the method of elicitation that causes the change in preference order, and perhaps ordering would be consistent within a method.

However, Mellers et al (in press) found that the rank order of attractiveness ratings could also be altered by changing the selection of stimuli presented to the subject for judgment. When the experimental design included positive, negative, zero and near zero outcomes, even ratings could be made to switch from an additive to a multiplicative relationship between probability and amount. The change in rank order could be explained by the assumption that the scales were invariant, but the process changed as a function of the task and the stimulus design. The present results also show that the rank order within a method can be changed, in this case by manipulation of point of view.

The present phenomena and the findings of Birnbaum and Sutton (in press) seem to belong in the same catalog of effects as the classic preference reversal because they refute simple, context-invariant theories in which objects have well-defined utilities that can be measured by simple models. However, these phenomena are distinct and pose new requirements on theories that attempt to account for both judgments of value and choices. $\underline{\text { Conclusions }}$ 
The present experiments have three important results: First, changes in point of view affect the rank order of judged value of gambles. Second, price judgments violate branch independence: The effect of a given branch is diminished when the number of outcomes is increased. Third, judgments violate dominance. These results can be described with reasonable accuracy by a configurally weighted model that has much in common with rankdependent utility theories, but which allows configural weights to depend on point of view and on the value of the outcomes. Configural weighting can be interpreted as the consequence of an attempt to minimize asymmetric losses. A special case of this theory led to a simple formulation that gave a fairly accurate account of the major features of the data. 


\section{References}

Allais, M. (1979). The foundations of a positive theory of choice involving risk and a criticism of the postulates and axioms of the American School. In M. Allais \& O. Hagen (Eds.), Expected utility hypothesis and the Allais paradox. Dordrecht: Reidel.

Anderson, T., \& Birnbaum, M. H. (1976). Test of an additive model of social inference. Journal of Personality and Social Psychology, 33, 655-662.

Becker, J., \& Sarin, R. K. (1987). Lottery dependent utility. Management Science, 33, 1367-1382.

Bell, D. E., \& Raiffa, H. (1988). Marginal value and intrinsic risk aversion. In D. Bell, H. Raiffa, \& A. Tversky (Eds), Decision making: descriptive, normative, \& prescriptive interactions. New York: Wiley.

Birnbaum, M. H. (1972). Morality judgment: Tests of an averaging model. $\underline{\text { Journal of }}$ Experimental Psychology, 93, 35-42.

Birnbaum, M. H. (1973). Morality judgments: Tests of an averaging model with differential weights. Journal of Experimental Psychology, 99, 395-399.

Birnbaum, M. H. (1974). The nonadditivity of personality impressions, Journal of Experimental Psychology (Monograph), 102, 543-561.

Birnbaum, M. H. (1982). Controversies in psychological measurement. In B. Wegener (ed.), Social attitudes \& psychophysical measurement. Hillsdale, N.J.: Erlbaum, 401-485.

Birnbaum, M. H. (1983). Perceived equity of salary policies, Journal of Applied Psychology, 68, 49-59.

Birnbaum, M. H. (1987). Searching for coherence in judgment and decision making. Invited address to Western Psychological Association Meetings, Long Beach.

Birnbaum, M. H., \& Jou, J. W. (1990). A theory of comparative response times and "difference" judgments. Cognitive Psychology, 22, 184-210. 
Birnbaum, M. H., \& Mellers, B. A. (1983). Bayesian inference: Combining base rates with opinions of sources who vary in credibility. Journal of Personality and Social Psychology, 45, 792-804.

Birnbaum, M. H., Parducci, A., \& Gifford, R. K. (1971). Contextual effects in information integration. Journal of Experimental Psychology, 8, 158-170.

Birnbaum, M. H., \& Stegner, S. E. (1979). Source credibility in social judgment: Bias, expertise, and the judge's point of view. Journal of Personality \& Social Psychology, 37, 48-74.

Birnbaum, M. H., \& Stegner, S. E. (1981). Measuring the importance of cues in judgment of individuals: Subjective theories of IQ as a function of heredity and environment. Journal of Experimental \& Social Psychology, 17, 159-182.

Birnbaum, M. H., \& Sutton, S. (in press). Scale convergence and utility measurement. Organizational Behavior and Human Decision Processes, 00, 000-000.

Birnbaum, M. H., \& Veit, C. T. (1974). Scale convergence as a criterion for rescaling: Information integration with difference, ratio, and averaging tasks. Perception \& Psychophysics, 15, 7-15.

Bostic, R., Herrnstein, R. J., \& Luce, R. D. (1990). The effect on the preference-reversal phenomenon of using choice indifference. Journal of Economic Behavior and Organization, 13, 193-212.

Breault, K. D. (1983). Psychophysical measurement and the validity of the modern economic approach: A presentation of methods and preliminary experiments. $\underline{\text { Social Science }}$ Research, 12, 187-203.

Chandler, J. P. (1969). STEPIT: Finds local minima of a smooth function of several parameters. Behavioral Science, 14, 81-82.

Chew, S. H., Karni, E., \& Safra, Z. (1987). Risk aversion in the theory of expected utility with rank dependent probabilities. Journal of Economic Theory, 42, 370-381. 
Coombs, C. H., Bezembinder, T. G., \& Goode, F. M. (1967). Testing expectation theories of decision making without measuring utility or subjective probability. Journal of Mathematical Psychology, 4, 72-103.

Daniels, R. L., \& Keller, L. R. (in press) Choice-based assessment of utility functions.

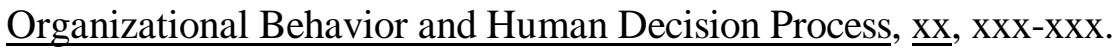

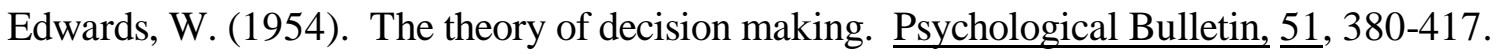

Edwards, W., von Winterfeldt, D., \& Moody, D. L. (1988). Simplicity in decision analysis; An example and a discussion. In D. Bell, H. Raiffa, \& A. Tversky (Eds) Decision making: Descriptive, normative, and prescriptive interactions. New York: Wiley.

Ellsberg, D. (1961). Risk, ambiguity and the Savage axioms. Quarterly Journal of Economics, 75, 643-649.

Fishburn, P. C. (1970). Utility theory for decision making. New York: Wiley.

Fishburn, P. C. (1983). Research in decision theory: A personal perspective. Mathematical Social Sciences, $\underline{5}, 129-148$.

Galanter, E. (1962). The direct measurement of utility and subjective probability. American Journal of Psychology, 75, 208-220.

Goldstein, W., \& Einhorn, H. J. (1987). A theory of preference reversals. Psychological $\underline{\text { Review }}$, 94, 236-242.

Grether, D. M., \& Plott, C.R. (1979). Economic theory of choice and the preference reversal phenomenon. American Economic Review, 623-638.

Harless, D. W. (1989). More laboratory evidence on the disparity between willingness to pay and compensation demanded. Journal of Economic Behavior and Organization, 11, 359-379.

Hershey, J. C., Kunreuther, H. C., \& Shoemaker, P. J. (1982). Sources of bias in assessment procedures for utility functions. Management Science, 28, 926-954.

Hershey, J. R., \& Schoemaker, P. J. (1985). Probability vs. certainty equivalence methods in utility measurement: Are they equivalent? Management Science, 31, 1213-1231. 
Kahneman, D., \& Tversky, A. (1979). Prospect theory: An analysis of decision under risk. Econometrica , 47, 263-291.

Karmarkar, U. S. (1978). Subjectively weighted utility: A descriptive extension of the expected utility model. Organizational Behavior and Human Decision Performance, $\underline{21}, 61-72$.

Karni, E., \& Safra, Z. (1987). "Preference reversal" and the observability of preferences by experimental methods. Econometrica, 55, 675-685.

Keeney, R., \& Raiffa, H. (1976). Decisions with multiple objectives: Preferences and value tradeoffs. NY: Wiley.

Keller, L. R. (1985). An empirical investigation of relative risk aversion. IEEE Transactions on Systems, Man, and Cybernetics, SMC-15, 475-482.

Knetsch, J. L. \& Sinden, J. A. (1984). Willingness to pay and compensation demanded: Experimental evidence of an unexpected disparity in measures of value. The Quarterly Journal of Economics, 99, 507-521.

Krantz, D. H., Luce, R. D., Suppes, P. \& Tversky, A. (1971). Foundations of measurement, Vol. 1. New York: Academic Press.

Kruskal, J. B. \& Carmone, F. J. (1969). MONANOVA: A FORTRAN-IV program for monotone analysis of variance. Behavioral Science, $\underline{14}$, 165-166.

Lichtenstein, S., \& Slovic, P. (1971). Reversals of preference between bids and choices in gambling decisions. Journal of Experimental Psychology, 89, 46-55.

Loomes, G., \& Sugden, R. (1982). Regret theory: An alternative theory of rational choice under uncertainty. The Economic Journal, 92, 805-824.

Lopes, L. (1990). Re-modeling risk aversion: A comparison of Bernoullian and rank dependent value approaches. In G.M. von Furstenberg (Ed.) Acting under uncertainty, Boston: Kluwer Academic Publishers.

Luce, R. D. (1986). Comments on Plott and on Kahneman, Knetsch, and Thaler. Journal of Business, 59, S337-S343. 
Luce, R. D. (in press, a). Where does subjective expected utility fail descriptively? of Risk and Uncertainty, $\mathrm{xx}, \mathrm{xxx}-\mathrm{xxx}$.

Luce, R. D. (in press, b). Rank- and sign-dependent linear utility models for binary gambles. Journal of Economic Theory, xx, xxx-xxx.

Luce, R. D., \& Fishburn, P. C. (in press). Rank- and-sign dependent linear utility models for finite first order gambles. Journal of Risk and Uncertainty, $\mathrm{xx}, \mathrm{xxx}-\mathrm{xxx}$.

Luce, R. D., \& Narens, L. (1985). Classification of concatenation measurement structures according to scale type. Journal of Mathematical Psychology, 29, 1-72.

Lynch, J. G. (1979). Why additive utility models fail as descriptions of choice behavior. Journal of Experimental Social Psychology, 15, 397-417.

Machina, M. J. (1982). Expected utility analysis without the independence axiom, Econometrica, 50, 277-323.

Mellers, B. A., \& Birnbaum, M. H. (1983). Contextual effects in social judgment. $\underline{\text { Journal }} \underline{\text { of }}$ Experimental Social Psychology, 19, 157-171.

Mellers, B. A., Ordoñez, L., \& Birnbaum, M. H. (in press) A change of process theory for contextual effects and preference reversals in risky decision making, Organizational Behavior and Human Decision Processes, 00, 000-000.

Mellers, B. A., Richards, V., \& Birnbaum, M. H. (in press). Distributional theories of impression formation. Organizational Behavior and Human Decision Processes, $\underline{\mathrm{xx}}$, $\mathrm{xxX}-\mathrm{XXX}$

Mellers, B. A., Weiss, R., \& Birnbaum, M. H. (in press). Violations of Dominance in Pricing Judgments, Journal of Risk and Uncertainty, xx, xxx-xxx.

Miyamoto, J.M. (1989). Generic utility theory: measurement foundations and applications in multiattribute utility theory. Journal of Mathematical Psychology, 32, 357-404.

Payne, J. W. (1973). Approaches to decision making under risk: Moments versus risk dimensions. Psychological Bulletin, $\underline{80}$, 439-463. 
Quiggin, J. (1982). A theory of anticipated utility. Journal of Economic Behavior and Organization, $\underline{3}$, 324-345.

Raiffa, H. (1968). Decision analysis. Reading, MA: Addison - Wesley.

Riskey, D. R., \& Birnbaum, M. H. (1974). Compensatory effects in moral judgment: Two rights don’t make up for a wrong. Journal of Experimental Psychology, 103, 171-173.

Savage, L. J. (1954). The foundations of statistics. NY: Wiley.

Schoemaker, P. J. (1982). The expected utility model: Its variants, purposes, evidence and limitations. Journal of Economic Literature, 20, 529-563.

Shanteau, J. (1974). Component processes in risky decision making. Journal of Experimental Psychology, 103, 680-691.

Shanteau, J. (1975). An information integration analysis of risky decision making. In M. Kaplan \& S. Schwartz (Eds.). Human judgment and decision processes. New York: Academic Press, p. 109-137.

Slovic, P. (1967). The relative influence of probabilities and payoffs upon perceived risk of a gamble. Psychonomic Science, 9 , 223-224.

Slovic, P., \& Lichtenstein, S. (1983). Preference reversals: A broader perspective, American Economic Review, 596-605.

Slovic, P., Lichtenstein, S., \& Fischhoff, B. (1988). Decision making. In R. C. Atkinson, R. J. Herrnstein, G. Lindzey, and R. D. Luce (Eds.), Stevens' Handbook of Experimental Psychology, Vol. 2. New York: Wiley.

Stevens, S. S. (1975). Psychophysics. New York: Wiley.

Stigler, G. J. (1950a). The development of utility theory. I. Journal of Political Economy, 58, 307-327.

Stigler, G. J. (1950b). The development of utility theory. II. Journal of Political Economy, 58, 373-396.

Tversky, A. (1967a). Additivity, utility, and subjective probability. Journal of Mathematical Psychology, 4, 175-201. 
Tversky, A. (1967b). Utility theory and additivity analysis of risky choices. Journal of Experimental Psychology, 75, 27-36.

Tversky, A. \& Kahneman, D. (1986). Rational choice and the framing of decisions,. Journal of Business, 59, S251-S278.

Tversky, A., Sattath, S., \& Slovic, P. (1988). Contingent weighting in judgment and choice. Psychological Review, 95, 371-384.

von Neumann, J. \& Morgenstern, O. (1947). Theory of games and economic behavior. Princeton, NJ: Princeton University Press.

von Winterfeldt, D. \& Edwards, W. (1986). Decision analysis and behavioral research. Cambridge: Cambridge University Press.

Wakker, P. (1989). Transforming probabilities without violating stochastic dominance. In E. E. Roskam (Ed.), Mathematical psychology in progress; Berlin: Springer.

Weber, E. U., Anderson, C. J., \& Birnbaum, M. H. (in press). A theory of perceived risk and attractiveness. Organizational Behavior and Human Decision Processes, 00, 000-000.

Yaari, M. E. (1987). The dual theory of choice under risk. Econometrica, 55, 95-115. 


\section{Footnotes}

${ }^{1}$ This work was supported by NSF Grant, SES 8921880, a Hughes Grant, and a Senior Faculty Fellowship from California State University, Fullerton. Thanks are due to Steven McCormick and Sara Sutton for their assistance, and to Kevin Birnbaum, Louis Narens, and R. Duncan Luce for suggestions on an earlier draft.

${ }^{2}$ Requests for reprints should be addressed to Michael H. Birnbaum, Department of Psychology, C. S. U. F., Fullerton, CA. 92634. 


\section{Figure Captions}

Figure 1. Utility function as an explanation of "risk aversion", and "risk seeking”. For example, if a subject equates the gamble ( $\$ 96, .5, \$ 0)$ to $\$ 24$, the subject is said to be "risk averse" and the utility function is assumed to be concave downward, as shown by the curve through the point $(\$ 24, .5)$.

Figure 2. Predictions of configural-weight theory. Upper row of panels show utility of 50-50 gambles as a function of the utility of outcome $\mathrm{x}$ with a separate curve for the utility of outcome y; panels from left to right show predictions for different values of $\mathrm{w}$ from -.5 to +.5 . Middle row of panels show corresponding indifference curves. Lower row of panels show relationship between estimated utility function and actual utility function if SEU model is applied to data generated by configural-weight theory.

Figure 3. Asymmetric loss functions and expected loss as a function of estimated value, for hypothetical example discussed in text.

Figure 4. Relative weight of a stimulus as a function of S(p), with a separate curve for each value of av, according to Expression 4.

Figure 5. Mean judgments of value as a function of Amount to win y with a separate curve for each level of Amount x. Filled circles show data values; lines show predictions of configural-weight theory, discussed in text. Upper row of panels have $\mathrm{p}(\mathrm{y})=.2$; in middle row, $\mathrm{p}(\mathrm{y})=.5$; and $\mathrm{p}(\mathrm{y})=.6$ in lower row. Left panels show buyer's prices; Right panels show seller's prices, and neutral's are shown in center (Experiment 1).

Figure 6. Mean judgments as a function of probability of winning larger amount (y, p, \$0), with a separate curve for each amount, and a separate panel for each point of view. Filled circles show data, and curves show predictions of configural-weight theory (Experiment 2).

Figure 7. Mean judgments of gambles between $\$ 0$ and $\$ 96$, as a function of probability to win $\$ 96$, with a separate curve for each point of view. Small range gambles are plotted on the right as a function of point of view. (Experiment 2) 
Figure 8. Violations of branch independence. Mean judgments of two and three outcome gambles as a function of Amount y. Filled circles and solid lines show mean judgments and predictions of configural-weight theory, respectively for 50-50 gambles to receive y or $\$ 8$. Open circles and dashed lines show mean judgments and predictions, respectively, for three outcome gambles with a .5 chance to receive y, a .4 chance to receive $\$ 5$ and a .1 chance to receive $\$ 16$. Crossovers of data and curves are violations of branch independence. (Experiment 1)

Figure 9. Violations of monotonicity. Mean judgments as a function of the probability of wining \$96, with a separate curve for the amount received otherwise. Crossovers are violations of monotonicity (dominance): at high levels of probability to win, gambles with $\$ 0$ as the lower outcome receive higher judgments (open circles) and predictions (dashed lines) than gambles with \$24 as the lower outcome (filled circles and solid lines). (Experiment 2)

Figure 10. Estimated utility function from configural-weight theory, fit to both experiments. Squares show estimated values; line shows $\mathrm{u}(\mathrm{x})=\mathrm{x}$.

Figure 11. Estimated weighting of lower-valued outcomes as a function of probability, according to simplified configural-weight theory. Open squares show S(p), which are weights of lower-valued, positive outcomes in the seller's point of view; weights in the buyer's and neutral's viewpoints are given by Equation 4, using $\mathrm{a}_{\mathrm{V}}=.71$, and .60 , respectively. When the lowest outcome is zero, weights are calculated using $S_{0}(p)$, shown as solid diamonds. 